\title{
A QUESTÃO DA FRAGILIDADE DOS REGISTROS DOS MODELOS E DESENHOS INDUSTRIAIS NÃO EXAMINADOS E NÃO PROTEGIDOS NO BRASIL EM CONTRAPONTO À LEGISLAÇÃO COMUNITÁRIA DA UNIÃO EUROPEIA
}

The question of the fragility of the records of the unseen and unprotected industrial models and designs in Brazil as opposed to the European Union's legislation

La cuestión de la fragilidad de los registros de los modelos y diseños industriales no examinados y no protegidos en Brasil en contraposición a la legislación comunitaria de la Unión Europea

Carla Eugenia Caldas Barros ${ }^{1}$

RECEBIBO 29/01/2019

APROVADO 30/01/2019

PUBLICADO 04/01/2019

Editor Responsável: Carla Caldas

Método de Avaliação: Double Blind Review

E-ISSN: 2316-8080

DOI: 10.16928

Resumo

Neste trabalho se desenvolve uma crítica ao contexto político, jurídico e econômico em que se inserem os modelos de utilidade e desenho industrial em comparação com a legislação da União Europeia. A partir de questões conceituais essenciais, inclusive da doutrina jurídica e da legislação aplicáveis à matéria, destaca-se a atual situação dos países subdesenvolvidos e em desenvolvimento, em especial, do Brasil, apontando-se os aspectos que lhes são negativos, recorrendo-se, para tanto, a um necessário recuo

\footnotetext{
${ }^{1}$ Professora Doutora em Direito das Reações Sociais pela PUC/SP, professora Titular aposentada da UFS autora de vários artigos e livros na área de propriedade Intelectual e Empresarial. Orcid https://orcid.org/0000-0002-5818-58.
} 
histórico, para caracterizar o sistema de império e subjugação imposto durante a Modernidade às relações entre os países, até hoje predominante. Defende-se, enfim, a importância dos modelos de utilidade e de desenho industrial como via indispensável e mais viável para a atualização tecnológica dos países em desenvolvimento e sua eficaz inserção na globalização, com especial ênfase para a situação legislativa brasileira em contraponto com a da União Europeia.

Palavras chaves: Desenho industrial. Modelo industrial. Convenções internacionais. Conflito de interesses. Desenhos e modelos não registráveis

Abstract

In this work, a critique of the political, legal and economic context in which utility models and industrial design are inserted in comparation with the European Union legislation. From the essential conceptual issues, including the legal doctrine and legislation applicable to the subject, the current situation of the underdeveloped and developing countries, especially Brazil, is highlighted, pointing out the negative aspects of it. , To do so, to a necessary historical retreat, to characterize the system of empire and subjugation imposed during modernity on relations between countries, until now predominant. Finally, the importance of utility models and industrial design as an indispensable and viable path for the technological updating of developing countries and their effective insertion in globalization is emphasized, with special emphasis on the Legislative Brazilian situation as opposed to that of the Union European Union.

Keywords: Industrial draw. Industrial model. International conventions. Conflict of interests. Non-registrable designs and models

Resumen

En este trabajo se desarrolla una crítica al contexto político, jurídico y económico en que se inserta los modelos de utilidad y diseño industrial en comparación con la legislación de la Unión Europea. A partir de cuestiones conceptuales esenciales, incluso de la doctrina jurídica y de la legislación aplicables a la materia, se destaca la actual situación de los países subdesarrollados y en desarrollo, en especial, de Brasil, apuntando a los aspectos que les son negativos, recurriendo para ello, a un necesario retroceso histórico, para caracterizar el sistema de imperio y subyugación impuesto durante la Modernidad a las relaciones entre los países, hasta hoy predominante. Se defiende, en fin, la importancia de los modelos de utilidad y de diseño industrial como vía indispensable y más viable para la actualización tecnológica de los países en 
desarrollo y su eficaz inserción en la globalización, con especial énfasis en la situación legislativa brasileña en contraposición a la de la situación legislativa brasileña, Unión Europea.

Palabras clave: diseño industrial. Modelo industrial. Convenciones internacionales. Conflicto de intereses. Dibujos y modelos no grabables.

\section{Introdução}

Trata-se de um estudo sobre a importância, a interdependência dos institutos de PI: modelos industriais e artísticos e desenhos. Este artigo visa apresentar as distinções doutrinárias conceituais destes institutos além de mostrar que as conceituações se interlaçam tanto a nível nacional como internacional. Entretanto, o estudo e a pesquisa vão muito mais além que a simples distinção doutrinária e jurisprudencial. Visam também analisar criticamente a legislação no plano internacional e se a mesma se coaduna com os interesses públicos nacionais.

Quanto às metodologias utilizadas foram as empíricas, na coleta de bibliografia referente ao estado da arte da temática proposta, a fim de se atingir de forma analítica e abstrata, um conclusão crítica sobre o assunto.

Quanto ao desenvolvimento da pesquisa esta se baseou, na dificuldade de definição do ordenamento jurídico adequado a reger os contratos internacionais em sede de desenhos e modelos industriais pois decorre da ausência de regulamentação sobre o tema de modelos e desenhos industriais não registrados. O conflito entre os diversos ordenamentos jurídicos, no caso em tela o ordenamento jurídico brasileiro e o da União Europeia, Regulamento 06/2002, a diversidade de convenções internacionais e a possibilidade de aplicação da lex mercatoria agravam ainda mais esta dificuldade. Considere-se ainda que as partes do mesmo contrato podem ser submetidas a diferentes ordenamentos jurídicos como se depreende no estudo em questão ora analisado e indaga-se como o Estado Brasileiro poderá atender ao interesse público social e coletivo face à fragilidade de nossa legislação em relação a desenhos e modelos industriais.

A distinção entre modelos industriais e desenhos/ e respectivamente desenhos/modelos artísticos existentes no plano nacional tem uma incidência direta na proteção desta criação no plano internacional. A proteção destes institutos jurídicos de PI vai se e estender, além fronteiras, para um jogo exteriorizado na Convenção de Haia, Convenção de Berna, Trips e a Convenção da União Europeia. É uma via de mão dupla esta proteção tanto nacional quanto internacional e também, por ser uma via de mão dupla tem o caráter integrativo e interdependente, fator decisivo para uma melhor compreensão dos institutos. Em sede de Dip pode-se falar o seguinte diz Patricia Faveret Hardman em sua monografia intitulada A Autonomia Privada nos contratos internacionais de acordo com o Direito Internacional Privado e o Direito Interno Brasileiro: Uma visão constitucional que 
:”A parte especial do Direito Internacional Privado abrange o estudo do Direito dos Contratos Internacionais. A ideia central do Direito Internacional Privado é dirimir os conflitos de leis no espaço, encontrando soluções para os conflitos nos quais as relações privadas estejam relacionadas a mais de um ordenamento jurídico, ligadas por um elemento de estraneidade. Este consiste no elemento caracterizador de um contrato internacional, que o liga a dois ou mais ordenamentos jurídicos nacionais. Citam-se como exemplos a nacionalidade estrangeira de um dos contratantes, o fato de um dos contratantes ser domiciliado no exterior, o pagamento fixado em moeda estrangeira ou no exterior, ou o cumprimento da obrigação principal no exterior". ${ }^{2}$

As referencias bibliográficas são tanto brasileiras como estrangeiras estando estas últimas em consonância com as últimas atualizações legais e jurisprudenciais.

"Desenho ou modelo» designa a aparência da totalidade ou de uma parte de um produto, resultante das características, nomeadamente de linhas, contornos, cores, forma, textura e/ou materiais do próprio produto e/ou da sua ornamentação." (Art. ${ }^{\circ}$ s $1 .^{\circ}$ a) da Diretiva e 3..$^{\circ}$ a) do Regulamento, infra em causa, tanto as criações estéticas, de ordem bidimensional quanto tridimensional, com relevância utilitária em suma, criações estéticas com relevância para a competitividade das empresas nos "Mercados", tanto em mercados de produtos elevada rotação quanto em setores tecnologicamente maduros e com uma relação, estreita, com a comunicação comercial, por estar na base das opções dos consumidores. $^{3}$ na União Europeia as indústrias criativas e culturais correspondem a 4,5\% do PIB e a quase $4 \%$ do emprego, isto é, respondendo por 8,5 milhões de empregos diretos além de muitas outras atividades económicas dependerem da dimensão estética dos respetivos produtos ou até serviços, como resulta dos estudos e deram lugar a políticas da UE:

\section{a Comunicação da Comissão Europa 2020: Estratégia para um crescimento inteligente, sustentável e inclusivo (COM(2010) 2020 final), de 3 de março}

\footnotetext{
${ }^{2}$ Disponível em http://pidcc.com.br/artigos/11022017/11.pdf, p. 311 acesso 24 abr 2017.

3 MASSENO, Manual David em Desenhos e modelos no Direito da União Europeia Disponível em https://www.academia.edu/29769185/Dos_Desenhos_ou_Modelos_no_Direito_da_Uni \%C3\%A3o Europeia, acesso em 23 mar 2017. Co- autor do presente artigo na parte internacional do Direito da União Europeia . Levantamento das leis europeias em matéria de desenhos industrial. Utilização do material publicado com a devida autorização do autor, Manuel Davi Masseno.
} 


\author{
o Livro Verde Realizar o potencial das indústrias \\ culturais e criativas (Com(2010) 183 final), de 27 de \\ abril
}

o Projeto de conclusões do Conselho [da U.E.] sobre as competências culturais e criativas e o seu papel no desenvolvimento do capital intelectual da Europa, de 10 de novembro de 2011, e ainda

o Programa Europa Criativa (2014-2020) (Regulamento (UE) n. ${ }^{\circ}$ 1295/2013 do Parlamento Europeu e do Conselho, de 11 de dezembro de 2013.

Quanto às Fontes Internacionais ${ }^{4}$

Existe um conjunto muito fragmentado e lacunas neste domínio: Assim, na Convenção da União de Paris para a Proteção da Propriedade Industrial, de 20 de março de 1883 (até Estocolmo, 1967), consta a proteção dos "desenhos ou modelos industriais" (Art. ${ }^{\text {os }}$ $1 .^{\circ} 2$ ) e $5 .^{\circ}$ quinquies), sem sequer os definir, assim como alguns traços mínimos do respetivo regime, no que se refere a prazos de prioridade (Art. ${ }^{\circ} 4^{\circ}$ A. 1), C. 1) e E. 1), à não caducidade por falta de exploração ou introdução de objetos semelhantes (Art. ${ }^{\circ} 5{ }^{\circ}$ B.) e um período de graça para os apresentados em exposições internacionais oficiais ou reconhecidas internacionalmente (Art. ${ }^{\circ} 11^{\circ}$ )

Já na Convenção de Berna para a Proteção das Obras Literárias e Artísticas, de 9 de setembro de 1886 (até Paris, 1971), entre as "obras literárias e artísticas", a serem protegidas, surgem "as obras de arte aplicada" (Art. ${ }^{\circ}$ 2. $^{\circ} 1$ ), acrescentando que "Os países da União, reservam-se a faculdade de determinar, nas legislações nacionais, $o$ âmbito de aplicação das leis referentes às obras de arte aplicada e aos desenhos e modelos industriais, assim como as condições de proteção de tais obras, desenhos e modelos, levando em conta as disposições do artigo 7.4) da presente Convenção [prazo mínimo de proteção de 25 anos]. Para as obras protegidas exclusivamente como desenhos e modelos no país de origem não pode ser reclamada, nos outros países unionistas, senão a proteção especial concedida aos desenhos e modelos nesses países; entretanto, se tal proteção especial não é concedida nesse país, estas obras serão protegidas como obras artísticas." (Art. ${ }^{\circ} 2 .^{\circ} 7$ )

\footnotetext{
${ }^{4}$ A nova configuração internacional, de interdependência entre as economias dos diversos países, acarretou uma transformação na forma pela qual as nações soberanas lidam com a repercussão de suas decisões no âmbito internacional dia Patricia Hardmann em sua monografia Autonomia Privada e o Direito Internacional, p. 12.Disponível em http://pidcc.com.br/artigos/11022017/11.pdf. Acesso em 08 nov 2018.
} 
Por sua vez, no TRIPS 5 - Acordo sobre Aspectos dos Direitos de Propriedade Intelectual Relacionados ao Comércio (Anexo 1C do Tratado de Marraquexe, que instituiu a Organização Mundial do Comércio), de 12 de abril de 1994, “Os Membros estabelecerão proteção para desenhos industriais criados independentemente, que sejam novos ou originais. Os Membros poderão estabelecer que os desenhos não serão novos ou originais se estes não diferirem significativamente de desenhos conhecidos ou combinações de características de desenhos conhecidos. Os Membros poderão estabelecer que essa proteção não se estenderá a desenhos determinados essencialmente por considerações técnicas ou funcionais [e] Os Membros terão liberdade para cumprir com essa obrigação por meio de lei sobre desenhos industriais ou mediante lei de direito autoral." (Art. $25 .^{\circ}$ n. ${ }^{\circ}$ s 1 e 2 in fine).

É sabido que o princípio da liberdade, consubstanciado na autonomia privada e na livre iniciativa, também confere respaldo à livre concorrência. Logo, não se pretende que o Estado deixe de intervir nas relações privadas. Esta intervenção estatal na autonomia da vontade das partes contratantes denominada heteronomia da vontade se dá para garantir a observância dos preceitos fundamentais constitucionalmente estabelecidos, de evidente interesse público quer social quer coletivo levando em consideração também mesmo diante da hipercomplexidade dos contratos internacionais, o princípio da boa fé que modernamente vem se contrapondo ao princípio da liberdade de contratar, o equilíbrio econômico e a função social do contrato

E ainda temos o Acordo de Haia para o Registro Internacional de Desenhos ou Modelos Industriais, de 6 de novembro de 1925 (até Genebra, 1999) e ainda o Acordo de Locarno que estabelece uma Classificação Internacional para os Desenhos ou Modelos Industriais (Classificação de Locarno), de 8 de outubro de 1968 a qual tem "um caráter administrativo" e não obriga as Partes "nem quanto à natureza nem quanto ao alcance da proteção do desenho ou modelo nesses países" (Art. ${ }^{\circ} 2 .^{\circ}$ n. ${ }^{\circ} 1$ )

\section{1 as Fontes Europeias}

Antes de mais, tem-se o Livro Verde sobre a proteção jurídica do desenhos e modelos industriais (III/F/5131/91, de Junho de 1991)

\footnotetext{
5 "Inexiste até o momento qualquer ato internacional que diga como se protegem os desenhos industriais (a CUP determina que se proteja, mas não diz como; e não o diz TRIPs) - há quem escolha regime germano ao de patentes, como os Estados Unidos ou o Brasil na Lei de 1971, e quem crie proteção a alheia a este regime. Vale dizer: para o desenho industrial se têm muitos regimes distintos nacionais, sem padronização, com escasso interesse quanto ao direito comparado; mas todos eles refletem, com expressões diversas, certos problemas de política pública que são comuns à natureza e emprego dessas criações. Assim, do ponto de vista dos interesse público relevante, e das propostas para a mutante conformação das leis, vale ter muita atenção às respostas legislativas dos outros países.” BARBOSA, Denis Borges . Da ornamentalidade e acessoriedade como características do desenho industrial Disponível em http://www.denisbarbosa.addr.com/arquivos/200/propriedade/da_ornamentalidade_acessoriedade_di.pdf, Acesso em 24 abr 2017.
} 
A QUESTÃO DA FRAGILIDADE DOS REGISTROS DOS MODELOS E DESENHOS INDUSTRIAIS NÃO

EXAMINADOS E NÃO PROTEGIDOS NO BRASIL EM CONTRAPONTO À LEGISLAÇÃO

COMUNITÁRIA DA UNIÃO EUROPEIA

E-ISSN: $2316-8080$

A Diretiva 98/71/CE do Parlamento Europeu e do Conselho de 13 de Outubro de 1998 relativa à proteção dos desenhos ou modelos

objetivo: harmonizar legislações nacionais díspares, para construir o Mercado Interno

E o Regulamento CE n. ${ }^{\circ}$ 6/2002 do Conselho de 12 de dezembro de 2001, relativo aos Desenhos ou Modelos Comunitários

objetivo: criar um regime unitário à escala continental, em articulação com o Instituto de Harmonização no Mercado Interno, agora Instituto da Propriedade Intelectual da União Europeia

o objeto subjaz uma distinção entre as criações com relevância estética utilitária / "industrial" e as propriamente artísticas:

"«Produto» designa qualquer artigo industrial ou de artesanato, incluindo, entre outros, os componentes para montagem de um produto complexo, as embalagens, os elementos de apresentação, os símbolos gráficos e os caracteres tipográficos, mas excluindo os programas de computador." (Art. ${ }^{\circ} 1 .^{\circ}$ b) da Diretiva e Art. $^{\circ}$ 3. ${ }^{\circ}$ b) do Regulamento) em suma, criações estéticas com relevância para a competitividade das empresas nos "Mercados" não, necessariamente, de 'design' de autor, também a decoração de espaços comerciais ou de serviços e os interfaces informáticos, assim como os menus e os ícones;

também, as formas de partes suscetíveis de serem integradas num produto complexo, sendo este "[...] qualquer produto composto por componentes múltiplos suscetíveis de serem dele retirados para o desmontar e nele recolocados para o montar novamente." (Art. ${ }^{\circ}$ s $1 .^{\circ} \mathrm{c}$ ) da Diretiva e $3 .^{\circ} \mathrm{c}$ ) do Regulamento) desde que o componente "[...] depois de incorporado no produto complexo, continuar visível durante a utilização normal deste último [e] $\mathrm{Na}$ medida em que as próprias caraterísticas visíveis desse componente preencham os requisitos de novidade e de carácter singular." (Art. ${ }^{\circ} 3 .^{\circ}$ n. ${ }^{\circ} 3$ a) e b) da Diretiva e $4 .^{\circ}$ n. 2 a) e b) do Regulamento.

\section{por definição, por conceito:}

"«Desenho ou modelo» designa a aparência da totalidade ou de uma parte de um produto, resultante das características, nomeadamente de linhas, contornos, cores, forma, textura e/ou materiais do próprio produto e/ou da sua ornamentação." (Art. ${ }^{\circ}$ s $1 .^{\circ}$ a) da Diretiva e $3 .^{\circ}$ a) do Regulamento) essencial é a aparência, isto é, a perseção sensorial, que o produto transmite aos adquirentes, enumeração de indícios, sem atenção a, eventuais, qualidades estéticas, exclui os 'designs' de processo ou de serviço, v.g., os 
inerentes à impressão 3D etambém excluirá os cheiros e os sons mas, o 'design' de interiores e exteriores, possivelmente, pode ser protegido por esta via.

os requisitos de proteção são dois: a novidade e o caráter singular (Art. ${ }^{\circ} \mathrm{s} 3 .^{\circ} \mathrm{n} .{ }^{\circ} 2 \mathrm{da}$ Diretiva e $4 .^{\circ}$ n. ${ }^{\circ} 1$ do Regulamento)

quanto à novidade, na Diretiva, a qual pressupõe o registro (Art. ${ }^{\circ}$ $3 .^{\circ}$ n. $\left.{ }^{\circ} 1\right)$

"Um desenho ou modelo será considerado novo se nenhum desenho ou modelo idêntico tiver sido divulgado ao público antes da data do pedido de registo ou, se for reivindicada uma prioridade, antes da data de prioridade. Consideram-se idênticos os desenhos e modelos cujas caraterísticas específicas difiram apenas em pormenores sem importância." $\left(\right.$ Art. $\left.^{\circ} 4 .^{\circ}\right)$

uma distinção básica:

quanto à novidade, no Regulamento (Art. ${ }^{\circ} 5 .^{\circ}$ n. $\left.{ }^{\circ} 1\right)$, temos

sem registro, se "[...] antes da data em que o desenho ou modelo para o qual é reivindicada proteção tiver sido pela primeira vez divulgado ao público.” (alínea a)

enquanto com registro, "[...] antes da data de depósito ${ }^{6}$ do pedido de registro do desenho ou modelo para o qual é reivindicada proteção ou, caso seja reivindicada prioridade, antes da data de prioridade." (alínea b)

porém, o critério não é universal:

“[...] considera-se que um desenho ou modelo foi divulgado ao público se tiver sido publicado na sequência do registo ou em qualquer outra circunstância, apresentado numa exposição, utilizado no comércio ou divulgado de qualquer outro modo, excepto se estes factos não puderem razoavelmente ter chegado ao conhecimento dos círculos especializados do setor em questão que operam na Comunidade, no decurso da sua actividade corrente, antes da data do pedido de registo ou, se for reivindicada uma prioridade, antes da data de prioridade. No entanto, não se considera que o desenho ou modelo foi divulgado ao público

\footnotetext{
${ }^{6}$ Segundo a diretiva europeia, em sede de DMCNE, em sede de desenhos e modelos, em questão de depósito existem três possibilidades segundo Marino , Laure: “ obtenir um ou plusieurs titres nationaux par um ou plusieurs dépots directs, obtenir plusieres titres nationaux par um seul depôt internationalle ou obternir um titre communautaire par um sel depôt. " Droit de la proprieté intelectuelle, Paris: Themis , 2913, p.392
} 
pelo simples facto de ter sido divulgado a um terceiro em condições explícitas ou implícitas de confidencialidade." (Art. ${ }^{\circ}$ s $6 .^{\circ}$ n. ${ }^{\circ} 1$ da Diretiva e $7 .^{\circ}$ n. ${ }^{\circ} 1$ do Regulamento)

mas, "Não se considera, no entanto, que o desenho ou modelo foi divulgado ao público pelo simples facto de ter sido dado a conhecer a um terceiro em condições explícitas, ou implícitas, de confidencialidade." (Art. ${ }^{\circ}$ s $6 .^{\circ}$ n..$^{\circ}$ s 2 e $7 .^{\circ}$ n. ${ }^{\circ}$ s 2 e 3 do Regulamento)

Sobre estas questões, tem-se o Acórdão do Tribunal de Justiça da União Europeia, de 13 de Fevereiro de 2014 (Processo C-479/12), H. Gautzsch Großhandel, sobre a divulgação ao público e a novidade de um DMUENR (Desenho ou Modelo da União Europeia Não Registado) ${ }^{7}$ além de estar previsto um "período de graça": "1. a divulgação de um produto não será tida em consideração se o desenho ou modelo para o qual é requerida proteção na qualidade de desenho ou modelo comunitário registado tiver sido divulgado ao público: a) Pelo criador, pelo seu sucessível ou por um terceiro com base em informações fornecidas pelo criador ou pelo seu sucessível ou na sequência de medidas por eles tomadas; e b) Durante o período de 12 meses que antecede a data de depósito do pedido ou, caso seja reivindicada prioridade, antes da data de prioridade. [este regime] é também aplicável se o referido desenho ou modelo tiver sido divulgado ao público em resultado de um abuso relativamente ao criador ou ao seu legítimo sucessor." (Art. ${ }^{\circ}$ s $6^{\circ}{ }^{\circ}$ n. ${ }^{\circ}$ s 2 e 3 da Diretiva e $7^{\circ}{ }^{\circ}$ n. ${ }^{\circ} 2$ e 3 do Regulamento.

\section{Quanto ao relativamente caráter singular:}

"Considera-se que um desenho ou modelo possui carácter singular se a impressão global que suscita no utilizador informado diferir da impressão global causada a esse utilizador por qualquer desenho ou modelo divulgado ao público antes da data do pedido de registo ou da prioridade." (Art. ${ }^{\circ} \mathrm{s} 5 .^{\circ}$ n. ${ }^{\circ} 1$ da Diretiva e $6 .^{\circ}$ n. ${ }^{\circ} 1$ do Regulamento) podendo divergir setoriamente, "Na apreciação do carácter singular é tomado em consideração o grau de liberdade de que o criador dispôs para a realização do desenho ou modelo." (Art. ${ }^{\circ}$ s 5..$^{\circ}$ n. ${ }^{\circ} 2$ da Diretiva e $6 .^{\circ}$ n. ${ }^{\circ} 2$ do Regulamento)

O critério é o de um "utilizador informado", inserido nos "círculos especializados do setor em questão que operam na Comunidade Europeia”, não necessitando de ser um

\footnotetext{
7 Existem também desenhos e modelos comunitários não registrados que porém tem uma proteção uniforme em todo território da União Europeia, no entanto somente por 03 anos. Segundo Marino, Laure, “ C"est une nouveauté extraordinaire et fort utile, surtout pour pretéger des dessins ou modéles exploités sur une si courte periode que la procédure du dépot s'avere trop loud. Cela permet aussi de benéficier d'une protection em cas d'oubli de dépot, ce qui est extremement aprecciable dans 1 ecas où le dessin ne peut pas non plus être protege par le Droit d'auteur, em raison de son absence d'originalité." Marino, Laure, op. Cit, p.393
} 
perito / especialista, tal como ocorre em sede de Patentes de Invenção ou de Modelos de Utilidade.

Tem-se o Acórdão do TJUE, de 20 de Outubro de 2011 (Processo C-281/10 ), PepsiCo, o qual enfrenta as questões relativas à "Impressão global diferente", ao grau de liberdade do criador e identificação do que se entende por "utilizador informado".

\section{as exclusões de proteção:}

as formas técnicas necessárias:

isto é, "As características da aparência de um produto determinadas exclusivamente pela sua função técnica;" (Art. ${ }^{\circ}$ s $7 .^{\circ}$ n. ${ }^{\circ} 1$ da Diretiva e $8 .^{\circ}$ n. ${ }^{\circ} 1$ do Regulamento)

distinção face à invenções, a serem protegidas por patentes ou modelos de utilidade, acentuar o "exclusivamente", tendo como critério a viabilidade de os mesmos resultados puderem ser obtidos por outra via com base na perspetiva de um "utilizador informado"

Assim o Acórdão do TJUE, de 14 de setembro de 2010, Lego (Processo C-48/09 P), a propósito da "função técnica", no contexto da registrabilidade de uma marca tridimensional.

bem como formas funcionais dos componentes de produtos complexos:

“[...] as características da aparência de um produto que devam necessariamente ser reproduzidas na sua forma e dimensões exatas para permitir que o produto a que o desenho ou modelo se aplica ou em que é incorporado seja ligado mecanicamente a outro produto, ou colocado dentro, à volta ou contra esse outro produto, de modo a que ambos possam desempenhar a sua função." (Art. ${ }^{\circ} \mathrm{s} 7 .^{\circ} \mathrm{n} .^{\circ} 2$ da Diretiva e $8 .^{\circ} \mathrm{n} .^{\circ} 2$ do Regulamento) quanto a este aspeto, temos o Despacho do Tribunal, de 20 de outubro de 2015, Kwang Yang Motor Co. (Processo T-10/08 DEP), a propósito de um desenho ou modelo comunitário registado que representa um motor de combustão interna com ventilador na parte superior salvo em situações de modularidade, a "regra Lego":

“[...] desde que a sua fìnalidade seja permitir uma montagem múltipla de produtos intermutáveis ou a sua ligação num sistema modular." (Art. ${ }^{\circ}$ s $7 .^{\circ}$ n. ${ }^{\circ} 3$ da Diretiva e 8. ${ }^{\circ}$ n. 3 do Regulamento), a ser lida em termos restritivos com base nas Regras de Defesa da Concorrência.

O direito sobre desenhos ou modelos, no Regulamento:

Antes de mais, o direito ao desenho ou modelo "pertence ao criador ou ao seu sucessível." e "se forem dois, ou mais [...], qualquer um tem direito a requerer [o desenho ou modelo] em benefício de todos." (14. ${ }^{\circ}$ n. ${ }^{\circ}$ s e 2$)$, porém, o mais comum é a 
criação ocorrer no contexto dum contrato de trabalho, nesse caso, o direito pertence ao empregador, empresa ou Estado (Art. ${ }^{\circ} 14 .^{\circ}$ n. ${ }^{\circ} 3$ ), mas não em caso de encomenda E, ainda "O criador tem o direito, tal como o requerente ou o titular de um desenho ou modelo comunitário registado, de ser mencionado nessa qualidade perante o Instituto e no registo. Se o desenho ou modelo resultar de um trabalho de equipa, a menção da equipa pode substituir a menção dos vários criadores." (Art. ${ }^{\circ} 18 .^{\circ}$ )

sobre a determinação da titularidade do direito, inclusive quando o desenho ou modelo resulta de uma encomenda, temos o Acórdão do Tribunal, de 2 de Julho de 2009, Fundación Española para la Innovación de la Artesanía (FEIA) (Processo C-32/08)

\section{quanto ao conteúdo do direito:}

"O registo de um desenho ou modelo confere ao seu titular o direito exclusivo de o utilizar e de proibir a sua utilização por terceiros, sem o seu consentimento [e] abrange, em especial, o fabrico, a oferta, a colocação no mercado, a importação, a exportação ou a utilização de um produto em que esse desenho ou modelo foi incorporado, ou a que foi aplicado, bem como a armazenagem desse produto para os mesmos fins." (Art. ${ }^{\circ} \mathrm{s}$ 12..$^{\circ}$. ${ }^{\circ} 1$ da Diretiva e $19 .^{\circ}$ n. ${ }^{\circ} 1$ do Regulamento) mesmo se em um setor com uma classe, ou subclasse, diferente, nos termos da Classificação de Locarno, embora possa não existir violação do direito (Art. ${ }^{\circ}$ s $10^{\circ}$ e $36^{\circ}$ 6) relevante é, sempre, a "impressão global" e podendo licenciar o seu uso, em termos exclusivos ou não exclusivos (Art. ${ }^{\circ}$ 32. ${ }^{\circ}$ do Regulamento).

Para os regimes harmonizados e para DMUER, o direito tem uma duração de 5 anos, renováveis até 25 , a contar da data do depósito (Art. ${ }^{\circ} \mathrm{s} 10 .^{\circ}$ da Diretiva e $12 .^{\circ}$ do Regulamento) enquanto o DMUNR será protegido por 3 anos, a contar da divulgação, desde que preencha os requisitos materiais (Art. ${ }^{\circ} 11 .^{\circ}$ )

e este exclusivo abrange:

"[...] abrange qualquer desenho ou modelo que não suscite no utilizador informado uma impressão global diferente [sendo que, na] apreciação do âmbito da proteção, será tido em consideração o grau de liberdade de que o criador dispôs na realização do seu desenho ou modelo." (Art. ${ }^{\circ}$ s 9. ${ }^{\circ}$ n. ${ }^{\circ}$ s 1 e 2 da Diretiva e $10 .^{\circ}$ do Regulamento)

as vias de proteção: 
a via europeia, a qual começa com o depósito dum pedido, ou na Instituição Nacional ou no IPIUE - Instituto da Propriedade Intelectual da União Europeia (Regulamento

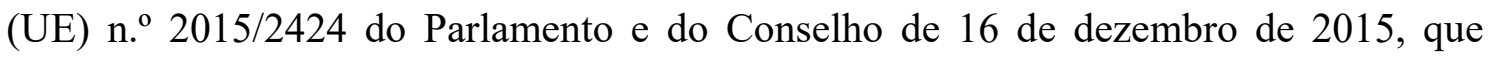
altera o Regulamento (CE) n.o 207/2009 do Conselho sobre a marca comunitária e o Regulamento (CE) n. ${ }^{\circ}$ 2868/95 da Comissão relativo à execução do Regulamento (CE) n. ${ }^{\circ}$ 40/94 do Conselho sobre a marca comunitária), também com descrição e representação do desenho ao modelo (Art. ${ }^{\circ}$ s $35 .^{\circ}$ e $36 .^{\circ}$ do Regulamento) o que implica que o IPIEU não realiza um exame substantivo do pedido (Art. ${ }^{\circ} 47 .^{\circ}$ do Regulamento), havendo lugar a recursos após a publicação do registo (Art. ${ }^{\circ}$ s $48 .^{\circ}, 49 .^{\circ}$ e $55 .^{\circ}$ e ss. do Regulamento)

Também através do procedimento constante do Acordo de Haia para o Registro Internacional de Desenhos ou Modelos Industriais, do qual a União Europeia passou a ser Parte desde 24 de setembro de 2007 e ainda resta a proteção, cumulativa, através do direito de autor:

"Qualquer desenho ou modelo protegido por um registo num Estado-membro de acordo com a presente diretiva [/ comunitário] beneficia igualmente da proteção conferida pelo direito de autor desse Estado a partir da data em que o desenho ou modelo foi criado ou definido sob qualquer forma. Cada Estado-membro determinará o âmbito dessa proteção e as condições em que é conferida, incluindo o grau de originalidade exigido." (Art. ${ }^{\circ} 17 .^{\circ}$ s da Diretiva e $96 .^{\circ}$ n. ${ }^{\circ} 2$ do Regulamento)

Quanto ao depósito internacional de desenhos se efetiva junto á OMPI, cuja proteção se dá " par le baisis de titres nationaux, dans tout ou partie des pays membres de 1"Arrangement de la haye. On evite ainsi une plénitude de dépôts. Chaque Office nationational vérifie ensuite la regularité de la demande" 8

Existe também o depósito comunitário na União Europeia que se dá perante a OHMI ou também pode se dar através de um escritório nacional. Este depósito permite que se obtenha o registro comunitário na União Europeia que se denomina pela sigla DMCE. O fato de ser um depósito comunitário não exclui o internacional, que este último por si só, por sua natureza, faz aumentar a proteção em espaço territorial,

\section{II - Evolução histórica dos modelos de utilidade}

O modelo de utilidade apareceu na legislação brasileira, pela primeira vez, no Decreto $n^{\circ} 16.264$, de 19 de dezembro de 1923, que criou a então Diretoria Geral de Propriedade Industrial. No parágrafo único de seu artigo 35, concebe os modelos de utilidade como as "[...] simples modificações introduzidas na disposição ou na forma de objetos conhecidos [...]".

Foram necessários quase 22 anos para que o modelo de utilidade recebesse

\footnotetext{
${ }^{8}$ MARINO, Laure, op. Cit. P.393.
} 
um tratamento legislativo melhor, por meio do Decreto-Lei $\mathrm{n}^{0}$ 7.903, de 27 de agosto de 1945, que instituiu um novo código de propriedade industrial, destinando-lhe um capítulo específico. No caput de seu artigo 10 consta: "Considera-se modelo de utilidade, suscetível de proteção, nos termos e condições do presente Código, toda disposição ou forma nova introduzida ou obtida em objetos conhecidos, desde que se preste a um trabalho ou uso prático".

Ademais, no primeiro parágrafo do mencionado dispositivo, é estabelecido que os modelos dizem respeito a "[...] ferramentas de trabalho ou de emprego prático, parte de máquinas ou utensílios de uso geral” e, ainda, é exigido, no parágrafo seguinte, que sua proteção somente é concedida "[...] à forma ou disposição nova, que traga à função, a que o objeto ou parte de máquina é destinado, melhor utilização. Enfim, no artigo 11 estão os modelos que não podem ser protegidos:

$1^{\circ}$ ) Os modelos que não apresentarem, até o pedido da patente, a característica de novidade, nos têrmos do art. $7^{\circ}, \S \S 1^{\circ}$ e $2^{\circ}$;

$2^{\circ}$ ) Os modelos que incidirem nas proibições do art. $8^{\circ}$;

$3^{\circ}$ ) os modelos que, pela sua natureza, constituírem matéria suscetível de proteção como patente de invenção, como modêlo ou desenho industrial, ou ainda como marca de indústrial ou de comércio;

$4^{\circ}$ ) Os modelos cujo uso ou aplicação não tenham fim lícito.

Apesar desses avanços, surge, com o Decreto-Lei $n^{\circ}$ 254, de 28 de fevereiro de 1967, um novo estatuto da propriedade industrial, que, além de revogar o anterior, ignora completamente o modelo de utilidade. Não foram necessários três anos para que surgisse o Decreto-Lei $\mathrm{n}^{\circ} 1.005$, de 21 de outubro de 1969, com novo estatuto para a propriedade industrial. Esse, para que não se diga que era inteiramente omisso, os modelos de utilidade recebem algum tratamento apenas em sede de disposições finais e transitórias, mesmo assim, de forma vaga, restrita a direitos já adquiridos.

Com o advento da Lei $\mathrm{n}^{0}$ 5.772, de 21 de dezembro de 1971, que instituiu um novo Código de Propriedade Industrial, os modelos de utilidades voltam a receber um tratamento expresso, sendo considerados, nos termos do artigo 10, quaisquer disposições ou formas novas obtidas ou introduzidas em objetos conhecidos, desde que prestem a um trabalho ou uso prático. Conforme esclarece o primeiro parágrafo desse dispositivo, o termo objetos refere-se a "[...] ferramentas, instrumentos de trabalho ou utensílios". Essa lei vigorou por quase 25 anos, uma vez que só foi revogada pela Lei ${ }^{\circ}$ 9.279/96, já abordada. 
No que toca ao modelo de utilidade, Denis Barbosa (2010) ressalta que as alterações introduzidas pela Lei $n^{\circ}$ 9.279/96 exigem "análise cuidadosa". Isso, porque no diploma anterior, a Lei $\mathrm{n}^{\circ}$ 5.772/71, exigia-se do modelo de utilidade, tão-somente, a novidade, a utilidade ou a aplicação industrial, introduzindo a lei vigente "[...] um requisito de atividade menor, nominalmente o 'o ato inventivo', definido como a forma ou disposição nova que não seja decorrência comum ou vulgar do estado da técnica". Em consequência, "a simples novidade, entendida como o distanciamento do estado da técnica, parece não ser suficiente para a concessão da proteção” (Ibidem).

O fato é que o modelo de utilidade se restringe ao invento de uma forma aplicável a uma ideia, o que permite entender que o ponto em comum, entre ele e a invenção propriamente dita, é finalidade, uma vez que de ambos se exige utilidade. É importante ponderar que a invento, em si mesmo, introduz inovação útil econômica e industrialmente, é fruto de ideia original, que introduz novo produto ou nova tecnologia, em vista do estado da técnica.

Já o modelo de utilidade é inovação restrita a invento já existente, mais é um melhoramento do que já existe, de forma que não se altere seu produto ou sua tecnologia, embora não se possa omitir o estado da técnica que lhe seja relacionável. Enfim, como ressalta Barbosa (Ibidem), "a proteção conhecida ao modelo de utilidade somente diz respeito à forma ou à disposição nova que traga melhor utilização à função a que o objeto ou parte da máquina se destina".

\section{internacional e nacional \\ III _Evolução histórica da legislação de desenhos industriais no plano}

Além da CUP, Trips temos o Tratado de Maastricht, também conhecido como Tratado da União Européia, foi assinado pelos Estados-Membros em 7 de Fevereiro em 1992, na cidade holandesa de Maastricht.

Em Outubro de 1998, entrou em vigor a Diretiva 98/71/EC30, com o objetivo de proteger o Desenho Industrial, ou seja, a aparência, a forma exterior e visível de um produto.

Nesse diapasão, a proteção deve conceder exclusividade a um desenho industrial novo e original, e, outrossim, vir a premiar o trabalho intelectual de seu criador.

Em meados de 2002, foi elaborado, pela Comissão Europeia, o Regulamento 1400/2002 (Lei Monti), especificando como se daria, a aplicação do $n^{0} 3$ do artigo 81 do Tratado quanto aos desenhos de peças de reposição no setor automobilístico. Foi assim que veio a surgir a "Cláusula de reparação"9 com a proposta da Diretiva 38 que tratou de revogar a Diretiva 98/71/EC. Esta cláusula contribuiu a proteger os consumidores como também

\footnotetext{
9 A criação da Cláusula de Reparação recepcionou no ordenamento da União Europeia a figura da competição aftermarket, ao permitir que a competição no aftermarket esteja de acordo com os princípios legais da concorrência, desenvolvidos pela jurisprudência da Corte Europeia de Justiça. Este fato legal desencadeou espaço para que a integração de uma solução legislativa na Lei de proteção do desenho industrial entre os Estados Membros do bloco europeu.
} 
aos fabricantes de veículos. Quanto aos primeiros, com esta cláusula, podem reparar seu veículo onde quiserem e com as peças de reposição que desejam e quanto aos últimos, garante os direitos dos fabricantes independentes de peças de reposição. Vê-se aí que há a sobreposição de direitos, pois existe a proteção oriunda da lei antitrust e a lei de propriedade intelectual - concorrência e marcas -.

Quanto ao plano nacional, ensina Gusmão, quanto aos desenhos industriais,

"A lei 9279/96 modificou drasticamente o regime de obtenção dos desenhos industriais que vigia até a sua promulgação - anteriormente tratado como patente ( desenho ou modelo industrial) conforme se tratasse de um objeto de duas ou em três dimensões. A sistemática adotada anteriormente, que submetia a proteção do design a exame e concessão de uma carta patente de fato se mostrou, na experiência brasileira absolutamente incompatível com o necessário e adequado tempo de obtenção de registro, (...) Boa parte da redação dos dispositivos da nova lei, entretanto, infelizmente ainda reflete grande influência dos conceitos, vocabulários e fórmulas do regime e procedimento patentário encontrados na lei anterior, apesar de ter simplificado sobremaneira o modo e o tempo de obtenção." 10

Quanto ao conceito e natureza jurídica dos desenhos industriais, ainda preleciona Gusmão:

"O registro dos desenhos industriais recai sobre um objeto estético, uma criação de forma que se apresenta em duas ou três dimensões que tenha um caráter essencialmente ornamental, como estipula a lei. Para ser concedido e gerar a proteção legal este objeto deve ser novo, original ${ }^{11}$ e servir de tipo de fabricação industrial. "12

\footnotetext{
${ }^{10}$ GUSMÃO, José Roberto in Desenhos Industriais, Tratado de Direito Comercial vol 6, São Paulo: Saraiva, 2015, p.282-283.

11 "Qual é a extensão da proteção dos desenhos industriais? A do desenho que descreve a criação ornamental, com suas variações permissíveis? Ou algo além? A questão está longe de ser abstrata. Quem percorre os precedentes judiciais - que são muitos - sobre infração de desenhos industriais constata que muito se litiga por desenhos que não são exatamente como os registrados, mas próximos. Gera-se assim um problema a ser resolvido: qual a aura de proteção de um desenho industrial? "Ressalto que a proteção conferida pelo registro de desenho industrial não é afastada caso haja pequena diferença entre o desenho protegido e sua cópia":

"Quanto à extensão da proteção conferida pelo registro, diferentemente de patentes de invenção ou de modelo de utilidade, que contém reivindicações que definem aquilo que é protegido, os registros de desenho industrial protegem objetos com o formato daquilo que é ilustrado. A proteção, em geral, estende-se a objetos tendo substancialmente o mesmo formato, o que inclui também objetos apenas ligeiramente diferentes daqueles que são ilustrados no registro." (Di Blasi Jr. et al., op. cit. P. 213/214.)" TJMG, AC 1.0452.10.003360-7/001, 12a Câmara Cível do Tribunal de Justiça do Estado de Minas Gerais, unânime, Des. José Flavio De Almeida, 22 de setembro de 2010" BARBOSA, Denis Borges . A extensão da originalidade como alcance de proteção em desenhos industriais, Disponível em http://www.denisbarbosa.addr.com/arquivos/200/propriedade/extensao\%20_originalidade.pdf, Acesso em 24 abr 2017, p.01
} 
O art. 95 da lei 9279/96 conhecida com a Lei da Propriedade Industrial trata do assunto.

Art. 95. Considera-se desenho industrial a forma plástica ornamental de um objeto ou o conjunto ornamental de linhas e cores que possa ser aplicado a um produto, proporcionando resultado visual novo e original na sua configuração externa e que possa servir de tipo de fabricação industrial.

Art. 94. Ao autor será assegurado o direito de obter registro de desenho industrial que lhe confira a propriedade, nas condições estabelecidas nesta Lei.

Parágrafo único. Aplicam-se ao registro de desenho industrial, no que couber, as disposições dos arts. $6^{\circ}$ e $7^{\circ}$.

Que segundo Gusmão esta propriedade seria "sui generis diante do caráter incorpóreo do bem e da temporalidade do direito, dispondo o seu titular das prerrogativas de uso, gozo, fruição e disposição, com caráter exclusivo"13.

O tempo de duração de registro incialmente será de 10 anos contados da data de depósito, podendo ser prorrogados por mais três períodos consecutivos de cinco anos cada um conforme preceitua o art. 108 da lei de propriedade industrial.

Cabe ressaltar que existem outros direitos de propriedade intelectual se sobrepondo na legislação de desenho industrial. Passa a existir uma cumulação de proteções. Pode-se encontrar direitos de marcas, direitos de autor transitando com suas peculiaridades próprias, no registro de desenho industrial, muito embora, todos se excluam.

$\mathrm{Na}$ legislação brasileira não é contemplada a questão dos desenhos e modelos não registrados,porém, protegidos pelo prazo de 03 anos. O que aqui, no ordenamento jurídico é disciplinado é o período de graça que é de 01 ano.

Apresentadas as legislações pertinentes aos modelos de utilidade e de desenhos industriais no ordenamento brasileiro e da União Europeia, em que, em que momento pode haver um conflito de interesses para o titular de registro de desenho industrial e modelo.

A legislação europeia traz embaraços ao nosso desenvolvimento?

Torna-se necessário, para tanto, um novo sistema de normas que regulem com eficácia as relações entre Estados, de forma que, inspirado no princípio social da propriedade, garanta os interesses comuns entre eles, sem a omissão do tão salutar princípio da razoabilidade. Ademais, que esse novo sistema de normas se concentre, especialmente, em promover alterações nas legislações nacionais, que, em certos casos, impedem o avanço tecnológico dos países que regem, por vários motivos, inclusive o de pressões de Estados estrangeiros. Em suma, urge uma nova ordem jurídica internacional para as inter-relações dos Estados, em sede de propriedade intelectual. Como conciliar

\footnotetext{
A citação que faz o julgado mineiro, ao falar de infração de objetos 1

12 Ibidem, p.284.

13 Ibidem, p. 284.
} 
os nossos interesses quando a legislação comunitária europeia concede proteção de 02 anos a desenhos e modelos não registrados?

A aplicação da norma jurídica internacional está sujeita a duas perspectivas: a primeira centraliza-se no Estado, cuja soberania o afirma acima de todos os demais sujeitos de direito, inclusive outros Estados, no que concerne a sua autoridade e supremacia em seu território; a segunda é descentralizada, uma vez que pauta na igualdade entre os Estados, constituindo-se, assim, o que se pode entender como sociedade internacional. Essa dicotomia tem reflexos importantes na realização da norma jurídica internacional, uma vez que fica ela pendente de validação pelas legislações nacionais.

Direcionando-se um olhar pragmático à questão, constata-se que a inexistência de uma entidade que responda pela efetiva aplicação das regras internacionais resulta, com frequência, em desvios que prejudicam o espírito das regras celebradas nas convenções internacionais, alcançando, inclusive, as legislações nacionais. Isso se deve, especialmente, à concepção de poder hoje dominante em todo o mundo, que tem seu sustento na supremacia da autoridade de fato, na capacidade de influir, determinar e governar. A vagueza do poder implica, de forma quase necessária, seu preenchimento. É praticamente natural que os mais favorecidos, indivíduos, sociedades ou Estados, assumam o direcionamento dos menos favorecidos, a não ser que esses reajam, recusando-se ou impondo-se a essa circunstância.

Não por outras razões, é muito importante que se debelem de vez as correntes doutrinárias que pugnam a favor da hierarquização das normais do Direito Internacional, para que nele prevaleçam, em suas plenitudes, os princípios da igualdade jurídica entre as nações e da não-intervenção. Essa é uma luta que mais cabe aos países menos favorecidos, eles é que têm a capacidade para promovê-la e vencê-la, a partir do entendimento de que não são possíveis os dominantes se não existem os dominados.

Uma das armas, sem dúvida, refere-se às transações com tecnologias. O fato é que tecnologias, especialmente as mais sofisticadas e complexas, sempre são transferidas de forma incompleta, já que desprovidas dos conhecimentos que lhes são inerentes. É próprio entender que, ainda que as tecnologias se relacionem a processos fabris, parte dos conhecimentos atinentes é propositadamente subtraída e as regionalizações das características de produtos, o que muito diz respeito a modelos de utilidade, é desenvolvidas pelos próprios detentores das tecnologias. São freqüentes os casos de modelos de utilidade desenvolvidos em alguns países, mas patenteados em outros, os o das origens das tecnologias. $\mathrm{O}$ fato é que não se observa qualquer estímulo, de qualquer ordem, privado ou estatal, ao desenvolvimento de modelos de utilidade aplicáveis a tecnologias importadas, isso quando ele não é totalmente desestimulado e até implicitamente proibido, o que é muito frequente. 
É totalmente pacífica a admissibilidade dos modelos de utilidade como modalidade patenteável no sistema jurídico internacional. Por exemplo, o Manual de Oslo, editado pela Organização para a Cooperação e Desenvolvimento Econômico (OCDE), é suficientemente claro quanto à questão. Em sua terceira edição, de 2005, considera como inovação (OECD, 2010):

a. implementação de um novo produto, bem ou serviço, ou um processo;

b. novo método mercadológico;

c. novo método organizacional nas práticas negociais;

d. nova modalidade de organização de local de trabalho ou relações externas.

A preocupação do manual, conforme é esclarecido em sua terceira edição, é a coleta de dados sobre a inovação em termos empresariais. Por conseguinte, exclui as mudanças de nível da indústria ou, mesmo, da economia, como o aparecimento de novos mercados, o desenvolvimento de novas fontes de matérias-primas, de produtos semi-elaborados ou a mera reorganização de uma indústria. Entretanto, admite estimativas sobre as amplas mudanças da indústria ou da economia, como é o caso o aparecimento da reorganização de um novo mercado ou indústria, desde que se verifique a agregação de informações benéficas a empresas individuais (Ibidem).

Por conseguinte, o novo, na análise da inovação, importa não só a novidade absoluta, nem a novidade relativa previstas em certos países, como é o caso da anterioridade por uso admitida pela lei americana. No contexto considerado, é pertinente, também, o novo tanto para quem pede a inovação quanto para quem pratica a inovação.

O fato é que, com base em ponderações de Denis Barbosa (2010), não há motivos para que um sistema de incentivo à invenção, em países em desenvolvimento e subdesenvolvidos, esteja limitado às consideradas grandes e nobres patentes de invenção e ou modelos de utilidade. É aceitável, pelo menos em caráter provisório, um sistema que recompense as inovações simples e melhoramentos de processos produtivos concretos, sem grandes ênfases nos questionamentos sobre a atividade inventiva e a novidade, em termos objetivos. Outro ponto importante é fazer com que as empresas incentivem, arrimadas em fontes de dados eficazes, as atividades inventivas em suas políticas internas, em seus denominados pátios de produção.

Em suma, há uma forte tendência, no atual Direito da Propriedade Intelectual, para reduzir as exigências quanto à originalidade e a criatividade, mais se privilegiando a garantia do retorno do investimento feito, do que o ato inventivo em si. Em vista disso, como assevera Denis Barbosa:

"Graças a tal tendência - e sem menor consideração pelos níveis mais restritos de inventividade dos países em desenvolvimento as regras do TRIPs não obrigam os países a instituírem qualquer 
sistema de proteção aos inventos menores e melhoramentos, deixando tal decisão ao critério nacional."

A opção pelo contributo mínimo, na conciliação eficiente dos interesses contrastantes, ajusta-se à função econômica do sistema de patentes ${ }^{14}$. Landes e Posner (2003) ressaltam que a questão direciona os monopólios instrumentais para uma questão econômica específica, já que as inovações implicariam uma incerteza dos resultados que desestimularia os investimentos necessários ${ }^{15}$. Em decorrência disso, haveria o risco a priorização de inovações menores, o que resultaria em um custo social que desestimularia o progresso técnico. ${ }^{16}$ Ademais, a eficácia social pretendida dependeria de avaliações permanentes da atividade inventiva, de forma que só se garantissem recompensas a graus relativamente elevados de contribuições.

"O sistema constitucional e legal brasileiro que reúne a proteção de patentes e a de desenhos industriais tem em comum a exigência de novidade e contributo mínimo: 10 essa distância mínima entre o simplesmente novo e o que representa uma criação digna de direito exclusivo. A noção de originalidade é a modalidade de contributo mínimo própria dos desenhos industriais, como a atividade inventiva o é das patentes de invenção." 17

Foi exatamente em virtude disso que surgiram severas críticas ao baixo nível de patentes americanas, especialmente nos setores de serviços financeiros e de

\footnotetext{
${ }^{14}$ Sobre a questão ver: Alan L. Duham (2007); Carlos M. Correa (2003, p. 410-431); Dan L. Burk e Mark a. Lemley (2003); Landes e Posner (2003, p. 304-306); Michael J. Meurer (2010); Robert M. Hunt (2010a, 2010b e 2010c);

15 Para Landes e Posner (2003, p. 304-306): "Were non-obviousness interpreted literally, it would add little to the requirements of utility and novelty, since if an invention is both useful and obvious, why hasn't it been discovered already? Maybe because an unexpected shift in demand and supply has suddenly made it useful and someone has to be the first to grasp the fact; but that is a special case. A more illuminating approach ties non obviousness to uncertainty and cost. Invention is a matter of adding to the stock of useful knowledge and so of reducing uncertainty. What is already known is not something waiting to be invented. But sometimes an idea is unknown not because it would be costly to discover but because it has no value. If some exogenous shock gives it value, it will be discovered more or less simultaneously by a number of those who can exploit it; there is no need to give exclusive rights to the first discoverer. But if it is costly to dispel uncertainty, then since the cost is incurred before a product embodying the invention can be brought to market, competitors will be tempted unless blocked by patents to sit back and wait until the invention is made and then sell copies, thus free riding on the inventor's cost of invention. Uncertainty and cost interact, in other words, as we also noted in regard to expressive works in Chapter 2. Uncertainty implies the likelihood of failures en route to success. Those failures are costly, and since the costs are incurred before the successful invention can be patented and marketed, they are additional fixed costs that the inventor must recover in the revenues generated by his patent".

16 "Uncertainty has a further significance. In his classic article on the economics of invention, Kenneth Arrow pointed out that risk aversion would result in underinvestment, from a social standpoint, in risky undertakings, such as invention. This point balances Arnold Plant's argument that patentability draws resources from what might be socially more valuable productive activities that do not offer monopoly returns. Unfortunately, the weights of these two offsetting factors are unknown" (Ibidem, idem).

17 BARBOSA, Denis Borges, A extensão da originalidade como alcance de proteção em desenhos industriais, Disponível em

http://www.denisbarbosa.addr.com/arquivos/200/propriedade/extensao $\% 20$ originalidade.pdf, Acesso em 24 abr 2017, p.01.
} 
programas de computadores, por força de jurisprudências de cortes inferiores ${ }^{18}$. A conseqüência foi a intervenção do Supremo Tribunal de Justiça dos Estados Unidos, que confirmou os parâmetros estipulados em 1966 por Grahan v John Deere ${ }^{19}$, em referência ao requisito da não-evidência da Lei de Patentes norte-americana, prestigiando-se, assim, o padrão constitucional.

Há um terceiro aspecto que não pode ficar no esquecimento: a exigência da atividade inventiva, em um país com poucos empenhos inovadores, é razão de um número menor de patentes de inventores locais do que o de inventores estrangeiros. Eduardo da Motta e Albuquerque ${ }^{20}$ observa:

Países desenvolvidos (com sistemas maduros) combinam inovações radicais com inovações incrementais próximas da fronteira tecnológica internacional. Inovações de primeira e de segunda geração têm lugar. As patentes de residentes desses países devem refletir essa qualidade. Mais atividades inovativas são passíveis de patenteação. Países em desenvolvimento (com sistemas imaturos) concentram as suas atividades tecnológicas na adaptação de tecnologias estrangeiras, na imitação, na cópia e em melhoramentos marginais, em outras palavras, em inovações de segunda e terceira geração. $O$ número de atividades inovativas relevantes em termos nacionais que são passíveis de patenteação é mais reduzido, quando comparado com os países de fronteira (ALBUQUERQUE, 2010).

Daí o entendimento de que convém um sistema suplementar em que não se dê a imposição da atividade inventiva e que favoreça os modelos de utilidade, não se olvidando a necessidade de nível de proteção que seja compatível com o desenvolvimento de inovações de segunda geração, como é o caso da adaptação.

Como preleciona Denis Borges Barbosa, Dois importantes aspectos, no entanto, impõem mutação legislativa urgente: (a) a questão das limitações do efeito dos DIs nos mercados secundários must match; (b) a questão da fragilidade dos registros não examinados.

Será que em questão a esta últimas ponderação do professor Denis Borges Barbosa transite nas questões se houve fim da acumulação total ( direito autoral e

\footnotetext{
${ }^{18}$ Ver Lee Petherbridge e R. Polk Wagner (2010) e, ainda, Centropia (2010).

${ }^{19}$ Apontam Bryan C. Diner e Scott M. K. Lee (2010): Many US patent practitioners expect that the Supreme Court ruling will effectively lower the threshold for determining the obviousness of an invention. Such a ruling will have a profound impact on patent owners, patent applicants, licensees, would-be infringers, and many others. But even before a decision has been issued, the US Patent and Trademark Office ("USPTO") has already made it more difficult to obtain a patent. In response to a wave of criticism over the grant of a number of specious patents in recent years, the USPTO has implemented various initiatives to improve patent quality, causing the patent allowance rate to drop from over $70 \%$ in 2000 to less than $55 \%$ in 2006.11 An expected lowering of the bar for determining obviousness will likely cause the allowance rate to further decline.
}

${ }^{20}$ Ver, também, Albuquerque, 1998. 
proteção de desenhos e ou modelos industriais em sede de legislação comunitária europeia?)

“(..) Introduz-se um rol específico de limitações, adaptando-se a referência (imperfeita) que se faz ao sistema de patentes, e acrescentando a limitação às peças must-match. Esta exige que para manter a limitação, em benefício do consumidor e para garantir as condições de concorrência leal, o elemento reposto deverá ser equivalente qualitativo da peça original. Introduz-se também uma cláusula geral, como a proposta no caso de patentes, incorporando-se a regra de três passos específica de TRIPs. Finalmente, propõe-se que qualquer pessoa, e não só o titular, possa pedir o exame a qualquer tempo, para, por exemplo, instruir nulidade ou fixar o risco de infringência." 21

Assim poder-se-ia resolver os conflitos de interesses quanto à utilização da lei internacional em contraponto à lei nacional que precisa adequar-se aos novos conceitos. E diante da fragilidade que a nossa legislação brasileira se encontra quanto aos desenhos e modelos não registrados, porém, protegidos pelo prazo de 03 anos na união europeia, esta precisa ser modificada .

Com a reforma de 2011 ocorrida na União Europeia houve sim o fim da acumulação total - direito autoral e proteção específica de desenhos e modelos, passando a existir a acumulação parcial em sede de direito autoral no requisito originalidade e as condições de novidades e de características próprias específicas da legislação de desenhos e modelos. Uma parte da doutrina considera que a acumulação entre direito autoral e a legislação específica fora mantida, permanecendo as mesmas condições tanto em sede de direito autoral bem como na legislação de desenhos e modelos.

\section{Conclusão}

Havendo tais impeditivos no Direito Internacional, nunca é tarde lembrar a autonomia das legislações nacionais. Elas não apenas exprimem os pensamentos e juízos de doutrinadores do Direito e de legisladores, pois também elas revelam os desígnios das nações, são vozes que mais cedo ou mais tarde ecoarão forte na comunidade das nações, fazendo valer seus justos propósitos.

Os modelos de utilidade, limitados que estão a melhoramentos ou aprimoramentos de peças, instrumentos, ferramentas e equipamentos, eles mais dizem

\footnotetext{
${ }^{21}$ BARBOSA, Denis Borges. Da nossa proposta de mudança das normas brasileiras relativas aos desenhos industriais Disponível em http://www.denisbarbosa.addr.com/arquivos/200/propriedade/proposta mudanca normas brasileiras di.pdf, Acesso em 24 abr 2017.
} 
respeito à inventiva de operários, engenheiros de linha de produção e outros tipos de usuários, inclusive pequenos inventores e artesãos. Eles, por conseguinte, se restringem a aperfeiçoamentos que conferem maior eficácia, comodidade ou manuseio mais fácil do objeto melhorado. Isso permite entender que os modelos de utilidade, tanto no plano inventivo quanto no de sua aplicação, diferem-se substancialmente das invenções de primeira geração, o que justifica um tratamento diferenciado e, talvez, até mesmo, mais flexível. No entanto, como observa Denis Borges Barbosa,

Os requisitos de concessão deste privilégio se alteraram na Lei 9.279/96, de forma que merece análise cuidadosa. Pela Lei 5.772/71 era exigível do Modelo de Utilidade tão simplesmente a novidade e a utilidade - ou aplicação industrial. [...] Curiosamente, a Lei 9.279/96 introduz para esta "patente menor" um requisito de atividade inventiva menor, nominalmente o "ato inventivo" definido como a forma ou disposição nova que não seja decorrência comum ou vulgar do estado da técnica (BARBOSA, 2003).

Complementa o autor:

A simples novidade, entendida como o distanciamento do estado da técnica, parece não ser suficiente para a concessão da proteção. No entanto, o que faz do modelo de utilidade um instrumento útil para os países como o Brasil é exatamente a inexistência do requisito de atividade inventiva: instrumento mais pedagógico, talvez, do que de mercado, esta patente reconhece avanços mínimos da produção industrial, dando-lhe proteção mais curta e menos vigorosa - exatamente por não exigir maior distância entre os níveis inventivos (Ibidem, idem).

O fato é de que há fortes indicativos de que, no atual sistema brasileiro, o que se reporta aos modelos de utilidade não atende com propriedade o princípio constitucional do equilíbrio de interesses: apesar de serem inovações de segunda geração, portanto, de menor carga inventiva, são protegidos por 15 anos, o mesmo prazo conferido às patentes; além disso, há o poder de exclusão, também o mesmo atribuído às patentes. Destarte, "a política dessa modalidade de privilégios clama por uma modificação atenta à sua função econômica, sob pena, de invalidação jurídica" (Ibidem, idem). A proteção nacional dos modelos e desenhos precisam se adaptar à legislação europeia no tocante aos desenhos e modelos não registrados, porém. protegidos por três anos. Ademais, no Brasil, não existem linhas de pesquisas essenciais ao desenvolvimento de inovações incrementais, tais como os modelos de utilidade, e nem mesmo financiamentos, tanto da parte da iniciativa privada quanto da pública. Por outro lado, os modelos de utilidade brasileiros, talvez por não atender aos interesses jurídicos e econômicos dos "major players" do mundo, em matéria de propriedade industrial, têm sido subutilizados, quando chegam a ser aproveitados, situação bem diversa das que ocorre em outros países. 
Certamente, uma das causas da subutilização é de natureza jurídica, já que os patenteamentos dos modelos de utilidade não recebem um tratamento legal específico, voltado às características que os distinguem das patentes de invenções. Daí a importância de estudos doutrinários e revisões legislativas e jurisprudenciais, introduzindo-se alterações e, até mesmo, inovações que se aprimore o sistema de patentes brasileiro, no sentido da otimização dos regramentos sobre os modelos de utilidade e desenhos industriais. E quanto aos desenhos industriais estes lhes faltam maior proteção no seio da concorrência, aqui no Brasil.

Os contratos internacionais conferem às partes contratantes inicialmente segurança jurídica bem como a justiça contratual com base no princípio da boa fé pois os contratos são a base do direito privado porém com a nova contratualidade e com a intervenção do estado para atender ao interesse público tem -se grandes desafios a fim de harmonizar as regras internacionais vigentes com o objetivo do equilíbrio econômico entre os estados membros. E só assim podermos equilibrar a fragilidade de nossa legislação quanto aos modelos e desenhos industriais, pois muitos ficam sem a devida proteção quando não estão registrados.

\section{Referências}

ABRANTES, Antonio Carlos Souza de. Patentes de modelo de utilidade no Brasil, Rio de Janeiro: Lumen Juris, 2014.

ALBUQUERQUE, E. M. Patentes de invenção de residentes no Brasil (1980-1995): uma investigação sobre o papel dos direitos de propriedade intelectual na construção de um sistema nacional de inovação. 1998. Tese (Doutorado em Economia da Indústria e da Tecnologia). Universidade Federal do Rio de Janeiro, Rio de Janeiro; Universidade of Sussex, Brington.

Patentes domésticas: avaliando estatísticas internacionais para localizar o caso brasileiro. Disponível em: <www.cedeplar.ufmg.br/pesquisas/td/TD\%20126.doc>. Acesso em: 26 jan. 2010.

BARBOSA, D. B. Uma introdução à propriedade intelectual. Rio de Janeiro: Lumen Juris, 2003. (a)

.Proteção dos modelos de utilidades e designs. Disponível em:

$<$ www.denisbarbosa.addr.com/127.doc >. Acesso em: 02 jan. 2010. (b)

A extensão da originalidade como alcance de proteção em desenhos industriais, Disponível em 
http://www.denisbarbosa.addr.com/arquivos/200/propriedade/extensao $\% 20$ originalida de.pdf, Acesso em 24 abr 2017. (c )

Da ornamentalidade e acessoriedade como características do desenho industrial

Disponível em

http://www.denisbarbosa.addr.com/arquivos/200/propriedade/da ornamentalidade aces soriedade di.pdf, Acesso em 24 abr 2017. (d)

. Da nossa proposta de mudança das normas brasileiras relativas aos desenhos

industriais Dusponivel em

http://www.denisbarbosa.addr.com/arquivos/200/propriedade/proposta mudanca normas brasileiras di.pdf, Acesso em 24 abr 2017. (e)

BARROS, C. E. C. Manual de Direito da Propriedade Intelectual. Aracaju: Evocati, 2007. (a)

Aperfeiçoamento e Dependência de patentes, Editora Lúmen Júris, Rio de Janeiro, 2004. (b)

. Proteção às Inovações Incrementais: modelo de utilidade e

insconstitucionalidade do prazo de proteção in Propriedade Intelectual Inovação e conhecimento, Marcos Machowicz e Guilllermo Palo Moreno ( organizadores), Curitiba: Juruá, 2010. (c).

BERTRAND, Andre. Marques et brevets Dessins et modèles, Paris: Delmas, 1995.

BRASIL. Constituição da República Federativa do Brasil de 1988. Disponível em: $<$ http://www.planalto.gov.br/ccivil_03/Constituicao/Constitui\%C3\%A7ao.htm>. Acesso em: 12 dez. 2009.

Constituição Política do Império do Brasil, de 25 de março de 1824. In: DIAS, F. A. (org.).Constituições do Brasil. Rio de Janeiro: Liber Juris, 1975.

Lei de 28 de agosto de 1930. Concede privilégio ao que descobrir, inventar ou melhorar uma indústria útil e um prêmio ao que introduzir uma indústria estrangeira, e regula sua concessão. Disponível em:

$<$ http://www6.senado.gov.br/legislacao/ListaPublicacoes.action?id=81564>. Acesso em 02 jan. 2010.

Lei $\mathbf{n}^{0}$ 5.772, de 21 de dezembro de 1971. Institui o Código da Propriedade Industrial, e dá outras providências. Disponível em: $<$ http://www.planalto.gov.br/ccivil_03/Leis/L5772.htm>. Acesso em: 02 jan. 2010.

Lei $\mathbf{n}^{\circ}$ 8.958, de 20 de dezembro de 1994. Dispõe sobre as relações entre as instituições federais de ensino superior e de pesquisa científica e tecnológica e as fundações de apoio e dá outras providências. Disponível em: $<$ http://www.planalto.gov.br/ccivil_03/Leis/L8958.htm>. Acesso em: 15 dez. 2009. 
A QUESTÃO DA FRAGILIDADE DOS REGISTROS DOS MODELOS E DESENHOS INDUSTRIAIS NÃO

EXAMINADOS E NÃO PROTEGIDOS NO BRASIL EM CONTRAPONTO À LEGISLAÇÃO

COMUNITÁRIA DA UNIÃO EUROPEIA

E-ISSN: $2316-8080$

Lei $n^{0}$ 9.279, de 14 de maio de 1996. Regula direitos e obrigações relativos à propriedade industrial. Disponível em:

$<$ http://www.planalto.gov.br/ccivil_03/Leis/L9279.htm>. Acesso em 12 dez. 2009.

Lei $\mathbf{n}^{0} \mathbf{1 0 . 9 7 3}$, de 2 de dezembro de 2004. Dispõe sobre incentivos à inovação e à pesquisa científica e tecnológica no ambiente produtivo e dá outras providências. Disponível em: <http://www.planalto.gov.br/ccivil_03/_Ato2004-

2006/2004/Lei/L10.973.htm>. Acesso em: 15 dez. 2009.

Decreto $\mathrm{n}^{0}$ 16.264, de 19 de dezembro de 1923. Cria a Diretoria Geral da Propriedade Industrial. Disponível em:

$<$ http://www6.senado.gov.br/legislacao/ListaPublicacoes.action?id=46832>. Acesso em: 04 jan. 2010.

Decreto-Lei $\mathbf{n}^{0}$ 7.903, de 27 de agosto de 1945. Código da Propriedade Industrial. Disponível em:

$<$ http://www6.senado.gov.br/legislacao/ListaPublicacoes.action?id=22147>. Acesso em: 04 de jan. 2010.

Decreto-Lei $\mathbf{n}^{0}$ 254, de 28 de fevereiro de 1967. Código da Propriedade Industrial. Disponível em:

$<$ http://www6.senado.gov.br/legislacao/ListaPublicacoes.action?id=191697>. Acesso em 04 jan. 2010.

. Decreto-Lei n⿳ 1.005, de 21 de outubro de 1969. Código da propriedade

Industrial. Disponível em:

$<$ http://www6.senado.gov.br/legislacao/ListaPublicacoes.action?id=196217>. Acesso em 04 jan. 2010.

BURK, D. L.; LEMLEY, M. A. Is Patent Law technology-specific? Virgínia Law

Review, Charlottesville, V. 89, p. 1575, 2003 [Available at:

$<$ http://cdsweb.cern.ch/record/519690>].

CENTROPIA, C. A. Patent Law viewed through an evidentiary lens: the 'suggestion test' as a Rule of Evidence. Available at:

$<$ http://papers.ssrn.com/sol3/papers.cfm?abstract_id=893965>. Access: Jan, 25, 2010.

COHEN, Denis . La protection Internationale des dessins et modèles, Paris:

Economica, 1999.

CORREA, C. M. Managing the provision of knowledge: the design of Intellectual Property Laws, in providing global public goods. Oxford Scholarship Online Monographs, Oxford, n. 22, p. 410-431, Feb. 2003. 
DINER, B. C.; LEE, S. M. K. Across the pond - the positions in the US and Europe. Available at:

$<$ http://www.finnegan.com/FCWSite/abc.aspx?url=http $\% 3 \mathrm{~A} \% 2 \mathrm{~F} \% 2 \mathrm{Fwww}$.finnegan.co m\%2Fnews\%2Fnewspdf.>. Access: Jan. 25, 2010.

DREYFUS, Natalie et THOMAS, Béatrice. Marques, Dessins et modèles, Paris: Delmas, 2002.

DURHAM, A. L. Patent symmetry. Boston University Law Review, Boston, v. 87, Dec. 2007 [Available at: <http://ssrn.com/abstract=982153>].

GAlloUX, J-C. Cours de la Droit de la Propriété Industrielle. Paris: Dalloz, 2003.

GAMA CERQUEIRA, J. Tratado da propriedade industrial, 1. Rio de Janeiro: Forense, 1946.

GUSMÃO, José Roberto d'Affonseca. Desenhos Industriais in Tratado de Direito Comercial, vol 6, Fabio Ulhoa Coelho ( organizador), São Paulo: Saraiva, 2015.

HARDMAN , Patricia Faveret A Autonomia Privada nos contratos internacionais de acordo com o Direito Internacional Privado e o Direito Interno Brasileiro: Uma visão constitucional, monografia apresentada para a conclusão do curso de Direito. Artigo Disponível em http://pidcc.com.br/artigos/11022017/11.pdf, acesso em 08 nov 2018.

HUNT, R. M. Economics and the design of patent systems. FBR of Philadelphia Working Paper, Philadelphia. Available at:

$<$ http://papers.ssrn.com/sol3/papers.cfm?abstract_id=975483>. Access: Jan. 26, 2010a.

Patentability, industry structure and innovation. Federal Reserve Bank of Philadelphia Working Paper, Philadelphia. Available at:

$<$ http://papers.ssrn.com/sol3/papers.cfm?abstract_id=295664>. Access: Jan. 15, 2005b.

Non-obviousness and the incentive to innovate: an economic analysis of intellectual property reform. Federal Reserve Bank of Philadelphia Working Paper, Philadelphia. Available at:

$<$ http://papers.ssrn.com/sol3/papers.cfm?abstract_id=160674>. Access: Jan. 23, 2010.

IDS. Instituto Dannemann Siemsen de Estudos da Propriedade Intelectual.

Comentários à lei da propriedade Intelectual. Rio de Janeiro: Renovar, 2005.

JOUVAN, Guillaume Blanc. Droit de la proprieté intelectuelle,Paris:Yuibert,2011.

LANDES, W. M.; POSNER, R. A. The economic structure of Intellectual Property

Law. Massachusetts: Harvard University Press, 2003.

LOUREIRO, L. G. A. V. A lei da propriedade industrial comentada (Lei n ${ }^{\circ}$ 9.279, de 14 de maio de 1996). São Paulo: Lejus, 1999. 
A QUESTÃO DA FRAGILIDADE DOS REGISTROS DOS MODELOS E DESENHOS INDUSTRIAIS NÃO

EXAMINADOS E NÃO PROTEGIDOS NO BRASIL EM CONTRAPONTO À LEGISLAÇÃO

COMUNITÁRIA DA UNIÃO EUROPEIA

E-ISSN: $2316-8080$

MARINO,Laure. Droit de lea proprieté intelectuelle, Paris: Thémis Droit,2013.

MASSENO, Manuel David, Slides sobre Desenho ou modelo industrial Na União Européia, disponível em

https://www.academia.edu/29769185/Dos_Desenhos_ou_Modelos_no_Direito_da_Uni \%C3\%A3o Europeia, acesso em 24 mar 2017.

MEURER, M. J. Business method patents and patent floods. Washington University Journal of Law and Policy, Forthcoming, Saint Louis. Available at:

$<$ http://papers.ssrn.com/sol3/papers.cfm?abstract_id=311087>. Access: Jan. 25, 2010.

NASCIMENTO, J. P. C. A natureza jurídica do direito sobre os bens imateriais.

Revista da ABPI, São Paulo, n. 28, p. 23-32, mai./jun. 1997.

OECD - ORGANISATION FOR ECONOMIC CO-OPERATION AND

DEVELOPMENT. Oslo manual. Guidelines for collecting and interpreting innovation data. Available at: <http://www.mct.gov.br/upd_blob/0005/5068.pdf $>$. Access: Jan. 26, 2010 .

ONU. Organização das Nações Unidas para Agricultura e Alimentação - FAO. Um bilhão de pessoas vivem com fome. Disponível em:

$<$ http://www.1billionhungry.org/home/pt/>. Acesso em: 17 jan. 2010.

PETHERBRIDGE, L.; WAGNER, R. P. The federal circuit and patentability: an empirical assessment of the Law of Obviousness. Available at:

$<$ http://papers.ssrn.com/sol3/papers.cfm?abstract_id=923309>. Access: Jan. 25, 2010.

PIMENTA, E. G. O direito da empresa e a proteção das invenções, dos modelos de utilidade, dos desenhos industriais e das marcas. Disponível em:

$<$ http://www.frb.br/ciente/2005.2/DIR/DIR.PIMENTA.F3.pdf $>$. Acesso em: 29 dez. 2009.

POLLAUD-DULIAN, F. Droit de la propriété industrielle. Paris: Montchrestein, 1999.

PONTES DE MIRANDA, F. C. Tratado de Direito Privado, 16. São Paulo: Revista dos Tribunais, 1983.

SANTOS, B. S. La globalización del Derecho. Los nuevos caminos de la regulación y la emancipación. Bogotá: Instituto Latinoamericano de Servicios Legales Alternativos, 1998. 